\title{
Bioanalysis
}

\section{Development and validation of an ELISA for quantification of soluble IFN- $\beta$ receptor: assessment in multiple sclerosis}

\begin{abstract}
Aim: The soluble isoform of the IFN- $\beta$ receptor (sIFNAR2) can bind IFN- $\beta$ and modulate its activity, although its role in autoimmune diseases remains unknown. Methods: A recombinant human sIFNAR2 protein was cloned, expressed and purified after which we developed and validated an ELISA for its quantification in human serum. Serum sIFNAR2 were assessed in multiple sclerosis (MS) patients and healthy controls. Results: The ELISA has a dynamic range of $3.9-250 \mathrm{ng} / \mathrm{ml}$ and a detection limit of $2.44 \mathrm{ng} / \mathrm{ml}$. Serum sIFNAR2 were significantly lower in untreated-MS patients than in healthy controls. Conclusion: The ELISA is suitable for quantification of sIFNAR2 in serum and should facilitate the study of sIFNAR2 in neuroimmunological diseases such as MS.
\end{abstract}

Multiple sclerosis (MS) is a T-cellmediated autoimmune disorder characterized by inflammation of the central nervous system, demyelination and axonal damage [1-3]. The cytokine IFN- $\beta$ is a key molecule in this disease, as it maintains the anti-inflammatory status of the immune system [4] and is one of the most widely used treatments for MS patients.

The biological activity of IFN- $\beta$ is mediated through interaction with the IFN $\alpha / \beta$ cell surface receptor (IFNAR), composed of two subunits, IFNAR1 and IFNAR2 [5]. IFNAR 2 bears the IFN- $\beta$-binding domain and IFNAR 1 is needed to form and stabilize the high-affinity IFN- $\beta$-receptor complex [6]. The IFN $\beta /$ IFNAR interaction activates a complex intracellular pathway that involves the JAK-STAT family proteins and concludes with a variety of biological responses, including antiviral, antiproliferative and immunomodulatory effects $[7,8]$.

Soluble cytokine receptors participate in the control of cytokine activity by modulating their binding to anchored membrane receptors and generating the biological response. These receptors can act as biological agonists, protecting the ligand from proteolysis, improving its stability, modu- lating ligand pharmacokinetics or decreasing clearance, or by acting as antagonists in competition with the cell surface receptor for ligand binding $[9,10]$. There are two major mechanisms for the generation of soluble receptors, alternative splicing of the RNA that encodes the cytokine receptor and cleavage of the membrane receptor [11]. The IFNAR2 subunit has three isoforms resulting from alternative splicing; the short form (IFNAR2.1/IFNAR2b) is a nonfunctional transmembrane protein, whereas the long form (IFNAR2.2/IFNAR2c) is a transmembrane protein that composes the functional receptor together with IFNAR1 [12]. The other transcript encodes the soluble receptor form, sIFNAR2 (IFNAR2.3/IFNAR2a). This protein, which lacks the transmembrane and cytoplasmic domains [13], is detected in body fluids [14] and bind type I IFN [15]. A modulatory function has been postulated for sIFNAR2 as an agonist or antagonist of IFN- $\beta$ bioactivity, depending on sIFNAR 2 concentration $[16,17]$. The contribution of sIFNAR2 in MS and other autoimmune diseases nonetheless remains unknown, although it might modulate not only endogenous IFN- $\beta$ but also exogenously administered therapeutic IFN- $\beta$ [17].
Teresa Órpez-Zafra' ${ }^{1}$ Jose Pavía², Maria J Pinto-Medel', Isaac Hurtado-Guerrero', Jose L Rodriguez-Bada', Elisa Martín Montañez ${ }^{2}$, Óscar Fernández ${ }^{1}$, Laura Leyva ${ }^{\ddagger}, 1$ \& Begoña Oliver-Martos*, $*, 1$ 'Unidad de Gestión Clínica de Neurociencias. Instituto de Biomedicina de Málaga (IBIMA), Hospital Regional Universitario de Málaga, Spain ${ }^{2}$ Departamento de Farmacología y Pediatría, Facultad de Medicina, Instituto de Biomedicina de Málaga (IBIMA). Universidad de Málaga, Spain *Author for correspondence: begoliver@gmail.com

${ }^{\ddagger}$ Authors contributed equally 


\section{Key terms}

Multiple sclerosis: A T-cell-mediated autoimmune disorder characterized by inflammation, demyelination and axonal damage of the central nervous system.

IFN- $\beta$ : Cytokine with antiviral, antiproliferative and immunomodulatory effects that acts through interaction with its cell surface receptor (IFNAR), composed of two subunits, IFNAR1 and IFNAR2.

sIFNAR2: Soluble isoform of the IFNAR2 subunit, generated by alternative splicing of the RNA encoding IFNAR2 or cleavage of membrane receptor, with ability to modulate the biological activity of IFN- $\beta$.

Validation: Is the confirmation, via extensive laboratory work, that the performance characteristics of an assay are suitable and reliable for intended analytical use.

Accuracy: The accuracy describes the closeness of mean test results obtained by the method to the true value (concentration) of the analyte.

Imprecision: The random dispersion of a set of replicate measurements and/or values expressed quantitatively by statistic such as standard deviation or coefficient of variation.

In this study, we cloned, expressed and purified a recombinant human sIFNAR2 protein, after which we developed and validated an enzyme-linked immunosorbent assay (ELISA) for its quantification in human serum. We applied the validated assay to quantify serum sIFNAR2 in MS patients and healthy controls.

\section{Materials \& methods}

\section{Cloning \& expression of recombinant soluble} IFNAR2

sIFNAR2 was cloned in the prokaryotic system pEcoliCterm 6xHN Linear (Clontech), which bears an ampicillin resistance gene. The insert was synthesized by PCR using specific primers and separated by agarose gel electrophoresis based on size (924 base pairs). The specific band was purified with the QIAquick Gel Extraction kit (Qiagen) and ligated to the plasmid using the In-Fusion Dry-Down pellet kit (Clontech) following manufacturer's instructions. Replicative bacteria (MAX Efficiency DH5 $\alpha$ Competent Cells [Invitrogen]) were transformed with the plasmid, seeded in lysogeny broth (LB)-agar plates supplemented with $100 \mu \mathrm{g} / \mathrm{ml}$ ampicillin and incubated $\left(37^{\circ} \mathrm{C}\right.$, overnight). Colony-forming units were isolated, seeded in LB supplemented with ampicillin and incubated overnight with agitation. The plasmid was purified with the PureYield Plasmid Miniprep System (Promega), the nucleotide sequence and correct reading frames were verified, and BL21(DE3) bacteria (Invitrogen) were transformed to express the recombinant protein sIFNAR2. The culture was grown in LB supplemented with ampicillin to an optical density (OD) of 0.8 $(\lambda=600 \mathrm{~nm})$ and protein expression was induced by adding $0.5 \mathrm{mM}$ isopropyl $\beta$-D-1-thiogalactopyranoside followed by incubation $\left(37^{\circ} \mathrm{C}, 4 \mathrm{~h}\right.$, with agitation). Bacteria were harvested, resuspended in lysis buffer containing a protease inhibitor cocktail (Roche), incubated for ( $30 \mathrm{~min}$, room temperature; RT) with constant shaking and sonicated. The suspension was centrifuged and the supernatant filtered.

Recombinant sIFNAR2 was purified on highcapacity $\mathrm{Ni}^{+2}$-iminodiacetic acid resin columns and detected in western blot with anti-IFNAR2 human MaxPab (Abnova) (Figure 1A). Recombinant sIFNAR2 was also identified by MALDI-TOF (Supplementary Figure 1).

\section{Standardization of a sandwich ELISA to detect SIFNAR2 \\ Reagents \& buffers}

The reagents and buffers are summarized in Supplementary Table 1.

\section{Serum samples}

Human serum samples were obtained from 137 untreated patients with relapsing-remitting MS defined according to the revised McDonald criteria [18], recruited from the Málaga Regional University Hospital (Malaga, Spain). The samples were always obtained when the patients were in clinical remission. As controls (HC), 88 unrelated age-matched healthy individuals were selected. Samples and HC were processed following standard procedures and frozen immediately after reception by the Málaga Hospital-IBIMA Biobank, as part of Andalusian Public Health System Biobank. All patients who participated in the study gave informed consent and protocols were approved by institutional ethical committees (Comité de Ética de la Investigación Málaga Nordeste).

Recombinant sIFNAR2 was quantified by densitometry analysis using a bovine serum albumin standard and analyzed with ImageJ software (Supplementary Figure 2). The sIFNAR2 standard curve was generated, and prepared freshly for each assay. The curve covered a range from 3.9 to $250 \mathrm{ng} / \mathrm{ml}$, using six serial dilutions of recombinant sIFNAR2. The reference standard throughout the validation process was a single lot of protein with $>95 \%$ purity.

\section{Definition of quality control/nominal value}

As quality controls $\left(\mathrm{QC}_{1}-\mathrm{QC}_{5}\right)$ we used five neat serum samples derived from the study population, as recommended by Valentin et al. [21]. These samples were analyzed in three duplicate assays and the mean of the three experiments was used as nominal value for intra- and inter-assay accuracy and imprecision assessments. 


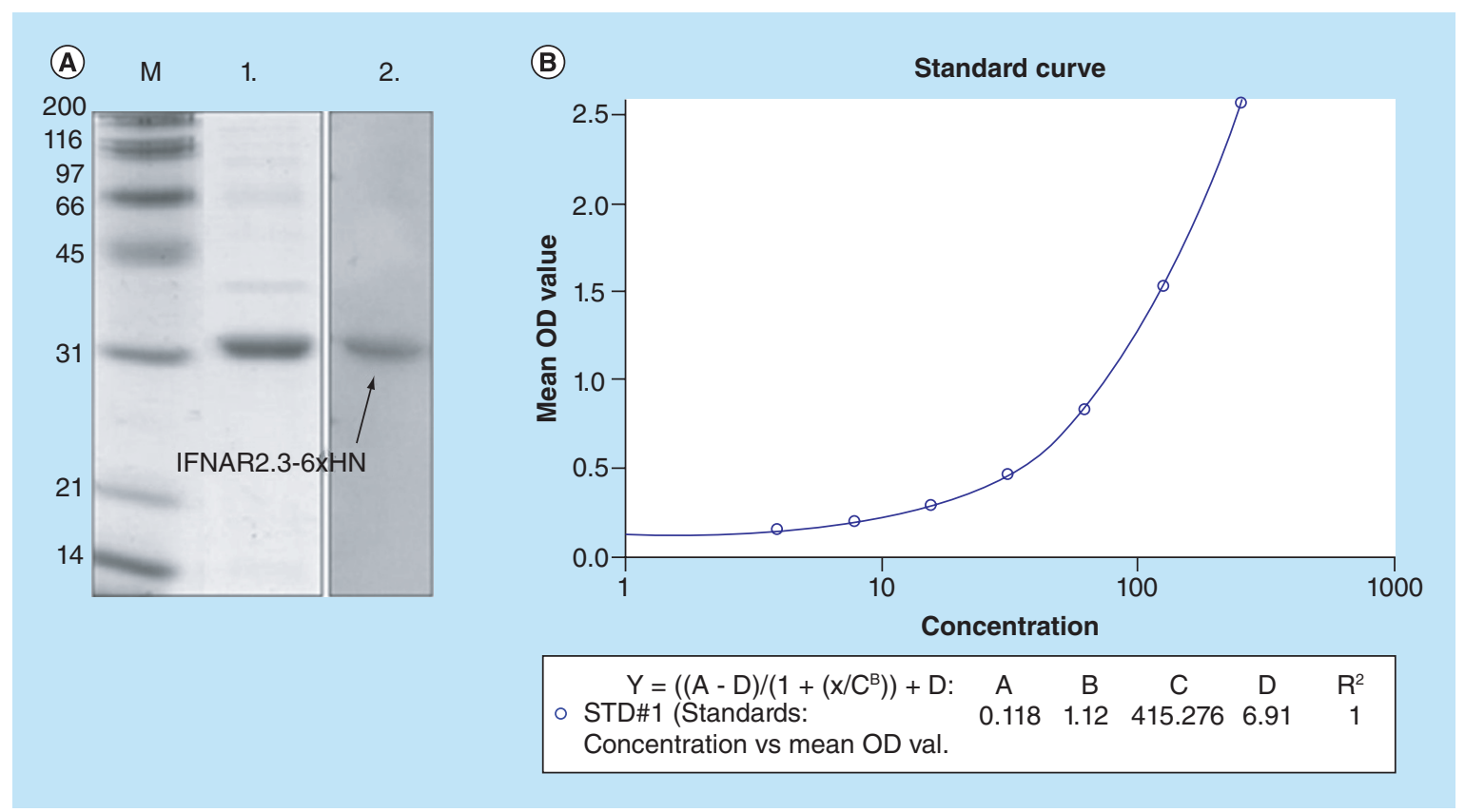

Figure 1. Detection of sIFNAR2 by western blot and standard curve of the ELISA. (A) Purified recombinant sIFNAR2 was resolved in $12 \%$ SDS-PAGE (1.), followed by western blot analysis using IFNAR2 purified MaxPab rabbit polyclonal and antibody and phosphatase alkaline-coupled goat anti-rabbit IgG. A colorimetric reaction using NBT/BCIP solution was used for visualization, which showed the $30 \mathrm{kDa}$ band corresponding to the size of purified sIFNAR2 (2.). (B) Representative standard curve of sIFNAR2. The correlation coefficient was equal to $1, y$-intercept $(A)$ was equal to 0.118 (the response value at 0 standard concentration), and the slope of the regression line (B) was 1.12. The estimated response at infinite standard concentration (D) was 6.91.

$\mathrm{M}$ : Molecular weight marker.

\section{ELISA}

This protocol describes the ELISA procedure used for the validation process. Concentrations of capture and secondary antibodies, as well as crossreactivity, $\mathrm{pH}$, incubation temperature and time were optimized previously (not shown).

Background signal obtained with all the possible combinations of the antibodies (capture, detection and enzyme-linked secondary antibodies), in the absence of sample, is shown in the Supplementary Figure 3, along with a standard curve and a negative control.

The strategy and steps followed for the development and validation of the ELISA are shown in Supplementary Figure 4.

Amino surface 96-well microtiter plates were coated with $0.2 \mu \mathrm{g}$ rabbit polyclonal antihuman IFNAR2 antibody (Abnova) in $100 \mu \mathrm{l} /$ well coating buffer $(0.05 \mathrm{M}$ carbonate-bicarbonate, $\mathrm{pH}$ 9.6) and incubated (overnight, $4^{\circ} \mathrm{C}$ ). Wells were then emptied, washed fourtimes with $300 \mu \mathrm{l} /$ well washing buffer (WB:Tris-buffered saline $+0.05 \%$ Tween-20) and blocked with 200 $\mu \mathrm{l} /$ well casein blocking buffer $(2 \mathrm{~h}, \mathrm{RT})$. The plate was washed four-times with WB, and $50 \mu$ standard curve or serum samples (diluted1:2) were added to wells in duplicate and incubated (1 h, RT). Blocking buffer was used as a blank. Plates were washed and $50 \mu$ mouse polyclonal antihuman IFNAR2 antibody $(1 \mu \mathrm{g} / \mathrm{ml}$ in assay buffer; Abnova) added per well and incubated $(1 \mathrm{~h}, \mathrm{RT})$. After three washes, $50 \mu \mathrm{l}$ horseradish peroxidase (HRP)-conjugated goat antimouse IgG $(\mathrm{H}+\mathrm{L})$ adsorbed against human immunoglobulins (diluted $1 / 10,000$ in blocking buffer; Southern Biotech) was added to each well and incubated $(1 \mathrm{~h}, \mathrm{RT})$. After three additional washes, $100 \mu \mathrm{l} /$ well TMB One Component HRP Microwell Substrate (BioFX Laboratories) was added and incubated (10-15 min, RT, in the dark). Color development was terminated by adding $50 \mu \mathrm{l} /$ well $1 \mathrm{~N} \mathrm{H}_{2} \mathrm{SO}_{4}$. Optical density (OD) was measured at 450 $\mathrm{nm}$ in a VERSAmax microplate reader.

\section{Sample analysis}

sIFNAR2 concentration in human serum samples was evaluated in duplicate. Each assay included a standard curve with seven concentrations, two quality controls and a negative control. The sIFNAR2 concentration was determined by OD interpolation from the samples and controls in the standard curve. The calibration curve was established using a four-parameter curve fitting model (Softmax Pro, Molecular Devices).

Sample measurement was considered acceptable if the coefficient of variation $(\mathrm{CV})$ of the duplicates was $<10 \%$ and the interassay CV of the standard was 


\section{Key terms}

Recovery: The quantified closeness of an observed result to its theoretical true value. It is used as a measure of accuracy.

$<20 \%$. Less than $2 \%$ of samples were below the lower limit of quantification and were not included as they were outside the calibration range.

\section{Validation of the sIFNAR2 assay in human serum}

The assay was validated following the Q2 (R1) Validation of Analytical Procedures of the ICH Harmonised Tripartite Guideline [19] and the recommendations of Lee et al. [20] and Valentin et al. [21].

\section{Statistical analysis}

The data were analyzed with SPSS 15.0 (SPSS, Chicago, IL, USA). Quantitative variables were reported as median and interquartile range. As a non-normal distribution was established in the Kolmogorov-Smirnov test, nonparametric Mann-Whitney U test was used to compare sIFNAR2 concentration between MS patients and controls. A $\mathrm{p}<0.05$ was considered statistically significant.

\section{Results}

\section{Calibration curve}

The curve was based on six serial dilutions of recombinant sIFNAR2 in blocking buffer and had a concentration range from 3.9 to $250 \mathrm{ng} / \mathrm{ml}$. Back-calculated concentration of the standard in the defined range met the acceptance criteria of mean accuracy within the range of $80-120 \%$ and imprecision less than $20 \%$ [21]. The standard recovery showed values from 97.46 to $107.55 \%$. The assay imprecision (CV) was $<5.1 \%$ for OD values and $<8.1 \%$ for the back-calculated values (Table $1 \&$ Figure 1B).

\section{Parallelism of sIFNAR2 assay}

Five serum samples were freshly diluted in sample diluent (blocking buffer) at 1:2, 1:4, 1:8 and 1:10 and evaluated to assess the parallelism of the assay. Accuracy of IFNAR determination in each sample was within the range of 103.18 to $130 \%$ compared with values determined at the 1:2 dilution, which complies with acceptance criteria for accuracy within the range of $70-130 \%$ (Table 2 \& Figure 2) [21].

This experiment demonstrated that the signal was produced by the analyte of interest, showed proportionality between the endogenous sIFNAR2 form and the reference standard, and that there was no apparent effect of dilution of human serum from 1:2 to $1: 10$ on sIFNAR2 determination. The mini- mum required dilution (MRD) to achieve acceptable accuracy and precision was thus 1:2.

\section{Spike \& recovery}

Five samples of human serum were spiked with $8 \mathrm{ng} / \mathrm{ml}$ (low spike) and $125 \mathrm{ng} / \mathrm{ml}$ (high spike) of recombinant human sIFNAR2 and accuracy was assessed at 1:2, 1:4, 1:8 and 1:10 dilutions in assay buffer. The spiking solution was $<5 \%$ of the final volume [22]. Accuracy was calculated using the sIFNAR2 concentration determined at dilution 1:2 as a reference value. The accuracy of measurement of spiked serum samples ranged from 90.14 to $122.87 \%$; for each dilution factor, the five samples thus met the acceptance criteria (Table 3). These data showed that the biological matrix does not interfere with the quantitative determination of sIFNAR2 in human serum.

\section{Assay dynamic range \& limits of quantification/detection}

The LLOQ is the lowest calibration point for which the concentration can be back-calculated on the regression curve with $80-120 \%$ accuracy and a CV below $20 \%$. The ULOQ is the upper calibration point that meets these criteria. The dynamic range thus extends from the LLOQs to ULOQs. In our assay, the dynamic range defined with recombinant sIFNAR2 ranged from 3.9 to $250 \mathrm{ng} / \mathrm{ml}$. In serum samples, the LLOQ, and therefore the sensitivity, was $7.8 \mathrm{ng} / \mathrm{ml}$ given the $1: 2$ predilution of the samples before analysis.

The LOD is the lowest concentration of a substance that can be distinguished from the absence of that substance, and its signal is therefore considerably higher than the background. The LOD was calculated from mean signal at background + three standard deviations. The LOD of the sIFNAR 2 assay, calculated from ten assays, was $2.44 \mathrm{ng} / \mathrm{ml}$.

\section{Repeatability}

Intra-assay accuracy \& imprecision of the standards

Three points of the standard curve $(250,62.5$ and $7.8 \mathrm{ng} / \mathrm{ml}$ ) were included five-times in duplicate in a single assay to evaluate repeatability. Intra-assay accuracy and imprecision were calculated for each standard level as the accuracy and mean imprecision of the five measurements. Nominal values for each standard were determined as the mean of the five determinations and were used as reference values for intra-assay accuracy and imprecision assessments. The accuracy was determined with the back-calculated concentration as the observed value and the nominal value as the expected value. Intra-assay accuracy was within 
Table 1. Example of data from calibration curve obtained during assay validation.

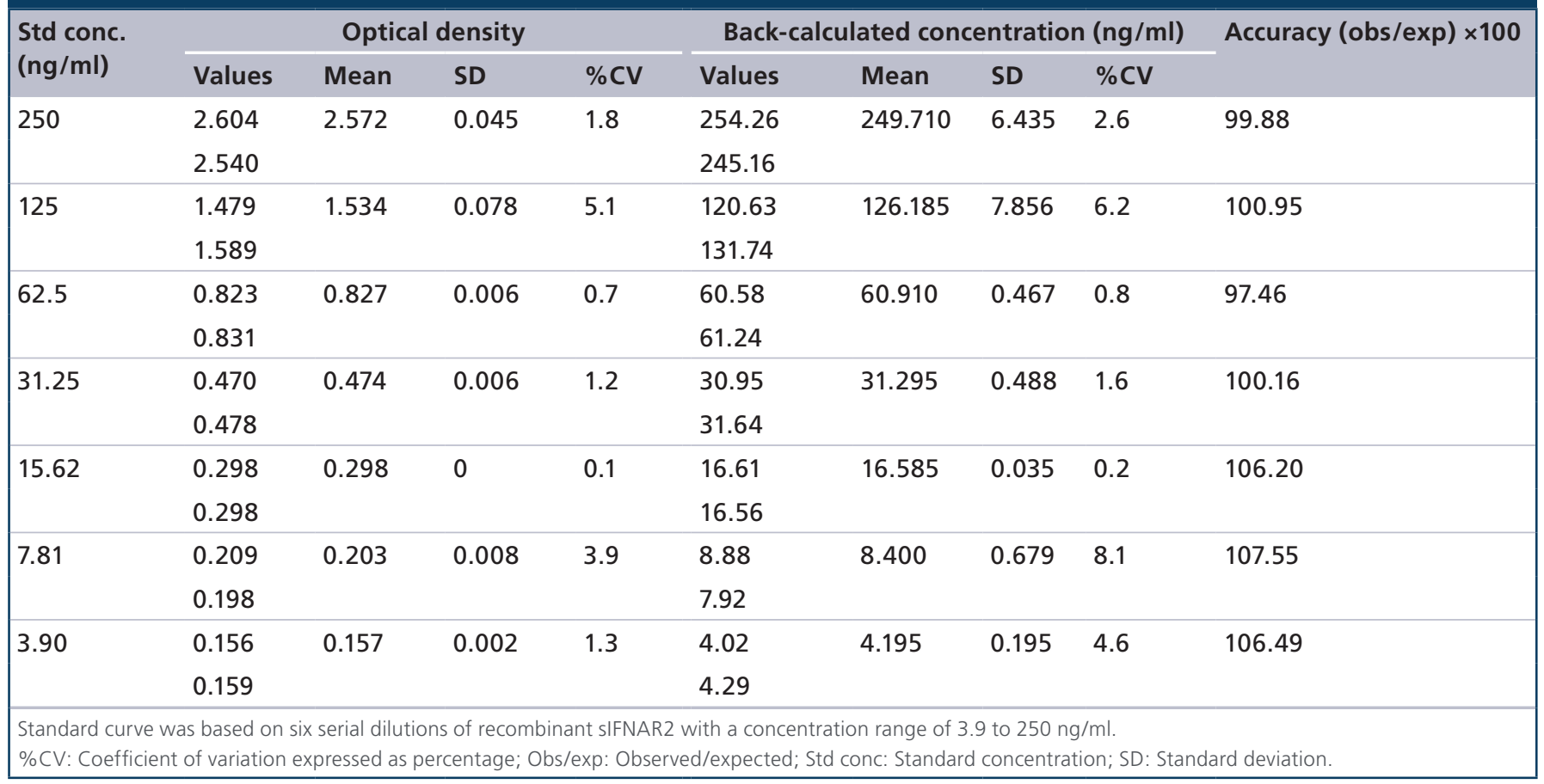

the range of 91.04 to $111 \%$ and imprecision $(\mathrm{CV})$ within the range of 4.24 to $8.32 \%$ (Table 4 ).

Intra-assay accuracy \& imprecision of the serum samples (QC)

Five serum samples were analyzed in duplicate fourtimes in a single run to evaluate ELISA repeatability. Nominal values of the samples were determined previously and were used as reference values for intra-assay accuracy and imprecision assessments. The intra-assay accuracy of the sIFNAR2 determination was within the range of 80.42 to $107.03 \%$; intra-assay imprecision with the back-calculated concentration ranged from 2.50 to 5.16\% (Table 4).

\section{Reproducibility}

Inter-assay accuracy \& imprecision of the standards Interassay imprecision was determined with three concentrations of the standard on five different days, performed by at least two different analysts. Interassay accuracy was calculated for each point with the back-calculated concentration and ranged from 86.54 to $112.69 \%$. Interassay imprecision was $0.24 \%$ for the highest concentration, $4 \%$ for medium concentration and $10.1 \%$ for the lowest concentration (Table 5).

\section{Interassay accuracy \& imprecision of the serum} samples (QC)

Five serum samples were assayed in five different experiments to evaluate the interassay variability. As before, nominal values of the samples were determined previously and used as reference values for interassay accuracy and imprecision assessments. Interassay accuracy of the sIFNAR2 determination ranged from 80.43 to $115.05 \%$, and imprecision with the back-calculated concentration from 3.9 to $16.6 \%$ (Table 5).

\section{Interference}

To test analytic interference from complex formation between sIFNAR 2 and IFN- $\beta$, five different sera were preincubated with each of the five IFN- $\beta$ concentrations (Betaferon 400, 800, 1200, 1600, 2000 IU) and without IFN- $\beta$. No analytical interference was observed when recombinant IFN- $\beta$ was added up to $2000 \mathrm{IU}$, since the accuracy ranged from 96.2 to $100.3 \%$, using the sIFNAR2 concentration without IFN- $\beta$ as the reference value.

\section{sIFNAR2 stability in serum}

sIFNAR2 stability in serum samples was analyzed with the same samples tested for interassay imprecision, after four cycles of freezing $\left(-20^{\circ} \mathrm{C}\right.$ for at least 8 weeks) and thawing (at RT for at least $3 \mathrm{~h}$ ). Recovery was assessed against the concentration measured at day 1 and ranged from 80.2 to $97.3 \%$ for the four samples. Only the sample with the lowest sIFNAR 2 concentration showed a percentage of recovery less than $80 \%$. The results showed that endogenous sIFNAR2 concentrations in human serum were stable for at least 8 weeks at $-20^{\circ} \mathrm{C}$ and after four freeze-thaw cycles. 


\begin{tabular}{|c|c|c|c|c|}
\hline & Dilution & OD values & $\begin{array}{l}\text { Mean adjusted } \\
\text { concentration }(\mathrm{ng} / \mathrm{ml})\end{array}$ & Accuracy (obs/exp $\times 100)$ \\
\hline \multirow[t]{4}{*}{ Sample 1} & $1 / 2$ & 0.845 & 110.10 & \\
\hline & $1 / 4$ & 0.536 & 119.32 & 108.37 \\
\hline & $1 / 8$ & 0.360 & 128.13 & 116.38 \\
\hline & $1 / 10$ & 0.302 & 116.14 & 105.49 \\
\hline \multirow[t]{4}{*}{ Sample 2} & $1 / 2$ & 0.995 & 155.60 & \\
\hline & $1 / 4$ & 0.665 & 160.55 & 103.18 \\
\hline & $1 / 8$ & 0.451 & 184.97 & 118.88 \\
\hline & $1 / 10$ & 0.384 & 178.97 & 115.01 \\
\hline \multirow[t]{4}{*}{ Sample 3} & $1 / 2$ & 0.916 & 122.17 & \\
\hline & $1 / 4$ & 0.578 & 132.47 & 108.43 \\
\hline & $1 / 8$ & 0.376 & 138.36 & 113.26 \\
\hline & $1 / 10$ & 0.344 & 148.30 & 121.39 \\
\hline \multirow[t]{4}{*}{ Sample 4} & $1 / 2$ & 0.781 & 99.36 & \\
\hline & $1 / 4$ & 0.504 & 109.07 & 109.77 \\
\hline & $1 / 8$ & 0.341 & 116.98 & 117.73 \\
\hline & $1 / 10$ & 0.308 & 120.62 & 121.39 \\
\hline \multirow[t]{4}{*}{ Sample 5} & $1 / 2$ & 0.825 & 106.85 & \\
\hline & $1 / 4$ & 0.570 & 129.89 & 121.57 \\
\hline & $1 / 8$ & 0.391 & 137.46 & 128.65 \\
\hline & $1 / 10$ & 0.335 & 139.11 & 130.20 \\
\hline
\end{tabular}

\section{Distribution of sIFNAR2 in serum of MS patients \& healthy controls}

The validated sIFNAR2 ELISA was used to determine sIFNAR 2 concentration in serum samples from 137 untreated MS patients and $88 \mathrm{HC}$. There were not significant differences in gender distribution among patients and controls. sIFNAR2 levels in MS patients (median [IR]: 71.67 [39.67-128.18 ng/ml]) were significantly lower than those in HC (median [IR]: 134.3 [76.10-179.21 ng/ml]; p <0.00001). A slight overlap was observed over the distribution ranges in the two subject groups (Figure 3).

We tested our recombinant sIFNAR2 protein with a commercial kit (VeryKine Human IFN Alpha/Beta Receptor 2 ELISA kit; cat. number 41,385) and the standard protein provided in the kit was included in the ELISA we developed. The distribution pattern of sIFNAR2 in serum of MS patients and $\mathrm{HC}$ as determined by the commercial kit was similar to that obtained with our ELISA (not shown).
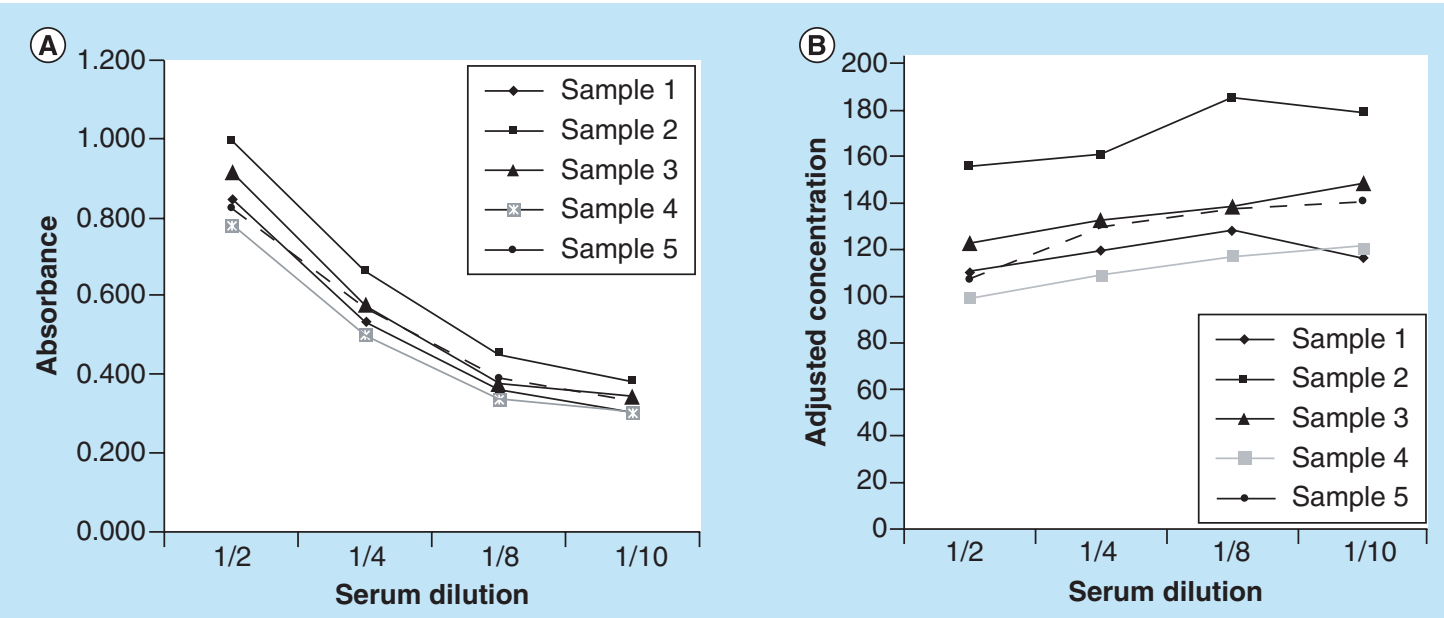

Figure 2. Parallelism assessment of sIFNAR2 assay in human serum. The data for five samples were plotted as absorbance versus $1 /$ dilution factor (A) and dilution-adjusted concentration versus 1/dilution factor (B). 
Table 3. Selectivity assessment of sIFNAR2 assay in human serum.

\begin{tabular}{|c|c|c|c|c|c|c|c|}
\hline \multirow[t]{2}{*}{ Sample } & \multirow[t]{2}{*}{ Dilution } & \multicolumn{3}{|c|}{ Low spike } & \multicolumn{3}{|c|}{ High spike } \\
\hline & & $\begin{array}{l}\text { Observed } \\
(\mathrm{ng} / \mathrm{ml})\end{array}$ & $\begin{array}{l}\text { Expected } \\
(\mathrm{ng} / \mathrm{ml})\end{array}$ & $\begin{array}{l}\text { Accuracy } \\
\text { (obs/exp } \times \\
100)\end{array}$ & $\begin{array}{l}\text { Observed } \\
(\mathrm{ng} / \mathrm{ml})\end{array}$ & $\begin{array}{l}\text { Expected } \\
\text { (ng/ml) }\end{array}$ & $\begin{array}{l}\text { Accuracy } \\
\text { (obs/exp } \times \\
100)\end{array}$ \\
\hline \multirow[t]{4}{*}{ S1 } & $1 / 2$ & 92.46 & & & 123.11 & & \\
\hline & $1 / 4$ & 49.51 & 46.23 & 107.09 & 64.09 & 61.55 & 104.11 \\
\hline & $1 / 8$ & 25.18 & 23.12 & 108.91 & 30.99 & 30.78 & 100.68 \\
\hline & $1 / 10$ & 20.21 & 18.49 & 109.29 & 23.54 & 24.62 & 95.61 \\
\hline \multirow[t]{4}{*}{ S2 } & $1 / 2$ & 122.54 & & & 132.03 & & \\
\hline & $1 / 4$ & 67.00 & 61.27 & 109.35 & 71.56 & 66.02 & 92.25 \\
\hline & $1 / 8$ & 32.03 & 30.63 & 104.54 & 40.26 & 33.01 & 121.98 \\
\hline & $1 / 10$ & 25.01 & 24.51 & 102.05 & 25.32 & 26.41 & 95.89 \\
\hline \multirow[t]{4}{*}{ S3 } & $1 / 2$ & 60.00 & & & 86.41 & & \\
\hline & $1 / 4$ & 31.01 & 30.00 & 103.36 & 42.62 & 43.21 & 98.65 \\
\hline & $1 / 8$ & 15.22 & 15.00 & 101.49 & 20.23 & 21.60 & 93.65 \\
\hline & $1 / 10$ & 12.36 & 12.00 & 103 & 18.12 & 17.28 & 104.85 \\
\hline \multirow[t]{4}{*}{ S4 } & $1 / 2$ & 144.77 & & & 227.93 & & \\
\hline & $1 / 4$ & 65.30 & 72.38 & 90.22 & 105.18 & 113.96 & 92.29 \\
\hline & $1 / 8$ & 38.83 & 36.19 & 107.30 & 55.79 & 56.98 & 97.90 \\
\hline & $1 / 10$ & 30.82 & 28.95 & 106.43 & 54.15 & 45.59 & 118.78 \\
\hline \multirow[t]{4}{*}{ S5 } & $1 / 2$ & 146.74 & & & 266.48 & & \\
\hline & $1 / 4$ & 71.90 & 73.37 & 98.00 & 120.10 & 133.24 & 90.14 \\
\hline & $1 / 8$ & 45.08 & 36.68 & 122.87 & 68.57 & 66.62 & 102.92 \\
\hline & $1 / 10$ & 35.22 & 29.35 & 120.00 & 56.90 & 53.30 & 106.75 \\
\hline
\end{tabular}

\section{Discussion}

sIFNAR2 is found in body fluids such as peripheral blood and urine [14]; although its function is not fully defined, it can bind type I IFN [15] and appears to modulate the bioactivity of endogenous and systemically administered IFN- $\beta[16,17]$. Despite the evidence that sIFNAR2 is a potential regulator of type I IFN responses [17], the role of sIFNAR2 in MS and in other immunological diseases is unknown.

Although biomarkers have become an important tool for optimizing the benefit/risk ratio of therapeutics, validated methods must be used in biomarker studies to improve the quality of the data and their application in clinical practice. Although previous studies have evaluated serum sIFNAR2 levels in diseases such as hepatitis C [23], AIDS [24] and neoplasms [25] proposing sIFNAR2 as a biomarker, none of these reports describe the detection method explicitly and no validated assays for sIFNAR2 measurement in serum have been reported. Here we describe the development, validation and implementation of a sensitive ELISA for quantification of sIFNAR2 in human serum.

Since no commercial sIFNAR2 peptide was available, we synthesized a recombinant sIFNAR2 in- house. The first step in the development was to clone, express and purify the recombinant sIFNAR 2 using a prokaryotic system. Recombinant sIFNAR2 was identified by western blot with the same antibodies used in the ELISA and then by MS (MALDI-TOF) and peptide mass fingerprinting, which confirmed the identity of the recombinant protein.

Throughout the validation process, we used a single batch of protein with a purity $>95 \%$ to generate the standards. The other reagents used in the assay were commercially available.

Incubation times, reagent concentrations and buffers used in the ELISA were optimized prior to validation to confirm the suitability and reliability of assay performance for measurement of sIFNAR2. The method was fully validated in human serum, although additional validation would be necessary for measurement of sIFNAR2 in matrices such as plasma or CSF.

The assay was shown to be accurate and precise over a dynamic range from 3.9 to $250 \mathrm{ng} / \mathrm{ml}$, and sensitivity in serum samples was $7.8 \mathrm{ng} / \mathrm{ml}$.

Experiments of linearity with serum samples were performed to demonstrate proportionality between the endogenous form of the biomarker and the reference standard, showing that the relationship between sIF- 


\begin{tabular}{|c|c|c|c|c|}
\hline Identification & Mean OD values & $\begin{array}{l}\text { Mean back-calculated } \\
\text { concentration }(\mathrm{ng} / \mathrm{ml})\end{array}$ & $\begin{array}{l}\text { Accuracy (obs/exp) } \\
\times 100\end{array}$ & $\begin{array}{l}\text { Intra-assay } \\
\text { imprecision }\end{array}$ \\
\hline \multicolumn{5}{|l|}{ Standards } \\
\hline $250(n=5)$ & $\begin{array}{l}2.084 \\
2.124 \\
2.045 \\
2.280 \\
2.018\end{array}$ & $\begin{array}{l}221.471 \\
227.149 \\
215.972 \\
250.165 \\
212.161\end{array}$ & $\begin{array}{l}98.26 \\
100.78 \\
95.82 \\
111.00 \\
94.13\end{array}$ & $\begin{array}{l}\text { Mean }=225.38 \\
S D=16.68 \\
\% C V=7.4\end{array}$ \\
\hline $62.5(n=5)$ & $\begin{array}{l}0.723 \\
0.733 \\
0.781 \\
0.762 \\
0.762\end{array}$ & $\begin{array}{l}58.252 \\
59.272 \\
64.198 \\
62.217 \\
62.249\end{array}$ & $\begin{array}{l}95.12 \\
96.79 \\
104.83 \\
101.60 \\
101.65\end{array}$ & $\begin{array}{l}\text { Mean }=61.23 \\
S D=2.6 \\
\% C V=4.24\end{array}$ \\
\hline $7.81(n=5)$ & $\begin{array}{l}0.220 \\
0.233 \\
0.230 \\
0.217 \\
0.222\end{array}$ & $\begin{array}{l}8.025 \\
9.358 \\
9.051 \\
7.732 \\
8.298\end{array}$ & $\begin{array}{l}94.49 \\
110.19 \\
106.57 \\
91.04 \\
97.71\end{array}$ & $\begin{array}{l}\text { Mean }=8.49 \\
\mathrm{SD}=0.70 \\
\% \mathrm{CV}=8.32\end{array}$ \\
\hline \multicolumn{5}{|l|}{ Serum samples } \\
\hline QC1 & 1.130 & 87.62 & 104.90 & Mean $=86.61$ \\
\hline QC1 & 1.150 & 89.41 & 107.03 & $S D=2.42$ \\
\hline QC1 & 1.089 & 83.83 & 100.36 & $\% C V=2.79$ \\
\hline QC1 & 1.108 & 85.58 & 102.45 & \\
\hline QC2 & 0.595 & 45.29 & 101.10 & Mean $=43.63$ \\
\hline QC2 & 0.575 & 42.97 & 95.93 & $S D=1.10$ \\
\hline QC2 & 0.572 & 43.32 & 96.70 & $\% C V=2.55$ \\
\hline QC2 & 0.582 & 42.96 & 95.90 & \\
\hline QC3 & 0.502 & 35.22 & 84.22 & Mean $=35.26$ \\
\hline QC3 & 0.503 & 35.42 & 84.69 & $S D=0.88$ \\
\hline QC3 & 0.502 & 34.78 & 83.17 & $\% C V=2.50$ \\
\hline QC3 & 0.510 & 35.65 & 85.25 & \\
\hline QC4 & 0.400 & 25.41 & 99.36 & Mean $=24.6$ \\
\hline QC4 & 0.389 & 23.78 & 93.01 & $S D=1.18$ \\
\hline QC4 & 0.405 & 25.82 & 101.00 & $\% C V=4.8$ \\
\hline QC4 & 0.381 & 23.41 & 91.55 & \\
\hline QC5 & 0.215 & 7.35 & 86.65 & Mean $=7.28$ \\
\hline QC5 & 0.213 & 6.83 & 80.42 & $S D=0.37$ \\
\hline QC5 & 0.216 & 7.74 & 91.16 & $\% C V=5.16$ \\
\hline QC5 & 0.215 & 7.22 & 85.07 & \\
\hline
\end{tabular}

NAR2 concentration and response in serum is similar to the reference standard measured in substitute matrix. The antibodies recognized recombinant and natural sIFNAR2 with equal efficacy.
Intra- and inter-assay precision and accuracy were determined with the standards, and also with serum samples used as quality controls to demonstrate similar ranges of variation in both. All parameters and 


\begin{tabular}{|c|c|c|c|c|c|}
\hline Identification & Assay & $\begin{array}{l}\text { Mean OD } \\
\text { values }\end{array}$ & $\begin{array}{l}\text { Mean back-calculated } \\
\text { concentration (ng/ml) }\end{array}$ & $\begin{array}{l}\text { Accuracy (obs/esp } \\
\times 100)\end{array}$ & $\begin{array}{l}\text { Interassay } \\
\text { imprecision }\end{array}$ \\
\hline \multicolumn{6}{|l|}{ Standards } \\
\hline \multirow[t]{5}{*}{250} & 1 & 2.572 & 249.71 & 99.80 & \multirow{5}{*}{$\begin{array}{l}\text { Mean }=250.213 \\
S D=0.603 \\
\% C V=0.24\end{array}$} \\
\hline & 2 & 2.636 & 249.85 & 99.86 & \\
\hline & 3 & 2.695 & 249.89 & 99.87 & \\
\hline & 4 & 2.310 & 251.17 & 100.38 & \\
\hline & 5 & 2.393 & 250.43 & 100.07 & \\
\hline \multirow[t]{5}{*}{62.5} & 1 & 0.827 & 60.91 & 96.88 & \multirow{5}{*}{$\begin{array}{l}\text { Mean }=62.874 \\
S D=2.541 \\
\% C V=4.04\end{array}$} \\
\hline & 2 & 0.664 & 61.83 & 98.35 & \\
\hline & 3 & 0.919 & 60.71 & 96.57 & \\
\hline & 4 & 0.785 & 66.67 & 106.05 & \\
\hline & 5 & 0.765 & 64.22 & 102.15 & \\
\hline \multirow[t]{5}{*}{7.8} & 1 & 0.204 & 8.40 & 112.69 & \multirow{5}{*}{$\begin{array}{l}\text { Mean }=7.457 \\
S D=0.758 \\
\% C V=10.1\end{array}$} \\
\hline & 2 & 0.171 & 7.96 & 106.79 & \\
\hline & 3 & 0.312 & 7.37 & 98.87 & \\
\hline & 4 & 0.247 & 7.09 & 95.12 & \\
\hline & 5 & 0.281 & 6.45 & 86.54 & \\
\hline \multicolumn{6}{|l|}{ Serum samples } \\
\hline \multirow[t]{5}{*}{ QC1 } & 1 & 1.087 & 83.74 & 100.245 & \multirow{5}{*}{$\begin{array}{l}\text { Mean }=86.81 \\
S D=3.4 \\
\% C V=3.9\end{array}$} \\
\hline & 2 & 1.083 & 83.33 & 99.755 & \\
\hline & 3 & 1.219 & 90.35 & 108.162 & \\
\hline & 4 & 1.243 & 86.35 & 103.374 & \\
\hline & 5 & 1.120 & 90.30 & 108.102 & \\
\hline \multirow[t]{5}{*}{ QC2 } & 1 & 0.629 & 46.72 & 104.31 & \multirow{5}{*}{$\begin{array}{l}\text { Mean }=43.9 \\
S D=1.93 \\
\% C V=4.3\end{array}$} \\
\hline & 2 & 0.572 & 42.86 & 95.69 & \\
\hline & 3 & 0.596 & 45.28 & 101.10 & \\
\hline & 4 & 0.573 & 42.97 & 95.93 & \\
\hline & 5 & 0.589 & 42.11 & 94.02 & \\
\hline \multirow[t]{5}{*}{ QC3 } & 1 & 0.662 & 44.91 & 107.40 & \multirow{5}{*}{$\begin{array}{l}\text { Mean }=39.3 \\
S D=4.29 \\
\% C V=10.9\end{array}$} \\
\hline & 2 & 0.528 & 38.72 & 92.60 & \\
\hline & 3 & 0.497 & 35.22 & 84.22 & \\
\hline & 4 & 0.491 & 35.41 & 84.69 & \\
\hline & 5 & 0.512 & 42.47 & 101.57 & \\
\hline \multirow[t]{5}{*}{ QC4 } & 1 & 0.436 & 28.17 & 110.18 & \multirow{5}{*}{$\begin{array}{l}\text { Mean }=25.09 \\
S D=1.98 \\
\% C V=7.9\end{array}$} \\
\hline & 2 & 0.371 & 22.96 & 89.82 & \\
\hline & 3 & 0.396 & 25.40 & 99.36 & \\
\hline & 4 & 0.384 & 23.78 & 93.01 & \\
\hline & 5 & 0.380 & 25.10 & 98.41 & \\
\hline \multirow[t]{5}{*}{ QC5 } & 1 & 0.239 & 9.76 & 115.05 & \multirow{5}{*}{$\begin{array}{l}\text { Mean }=8.09 \\
S D=1.34 \\
\% C V=16.6\end{array}$} \\
\hline & 2 & 0.198 & 7.21 & 84.95 & \\
\hline & 3 & 0.216 & 7.35 & 86.65 & \\
\hline & 4 & 0.201 & 6.82 & 80.43 & \\
\hline & 5 & 0.229 & 9.31 & 109.78 & \\
\hline
\end{tabular}

their accuracy and imprecision meet the acceptance criteria for ELISA validation [21].

As sIFNAR2 is able to bind endogenous IFN- $\beta$ [15], serum samples were preincubated with IFN- $\beta$ to evaluate whether the addition of this sIFNAR2 ligand interferes with antigen-antibody interaction in the ELISA, showing no analytical interference.

In terms of stability, we found no alterations in sIFNAR2 after repeated freeze-thaw cycles or sample storage for up to 2 months, which shows the util- 


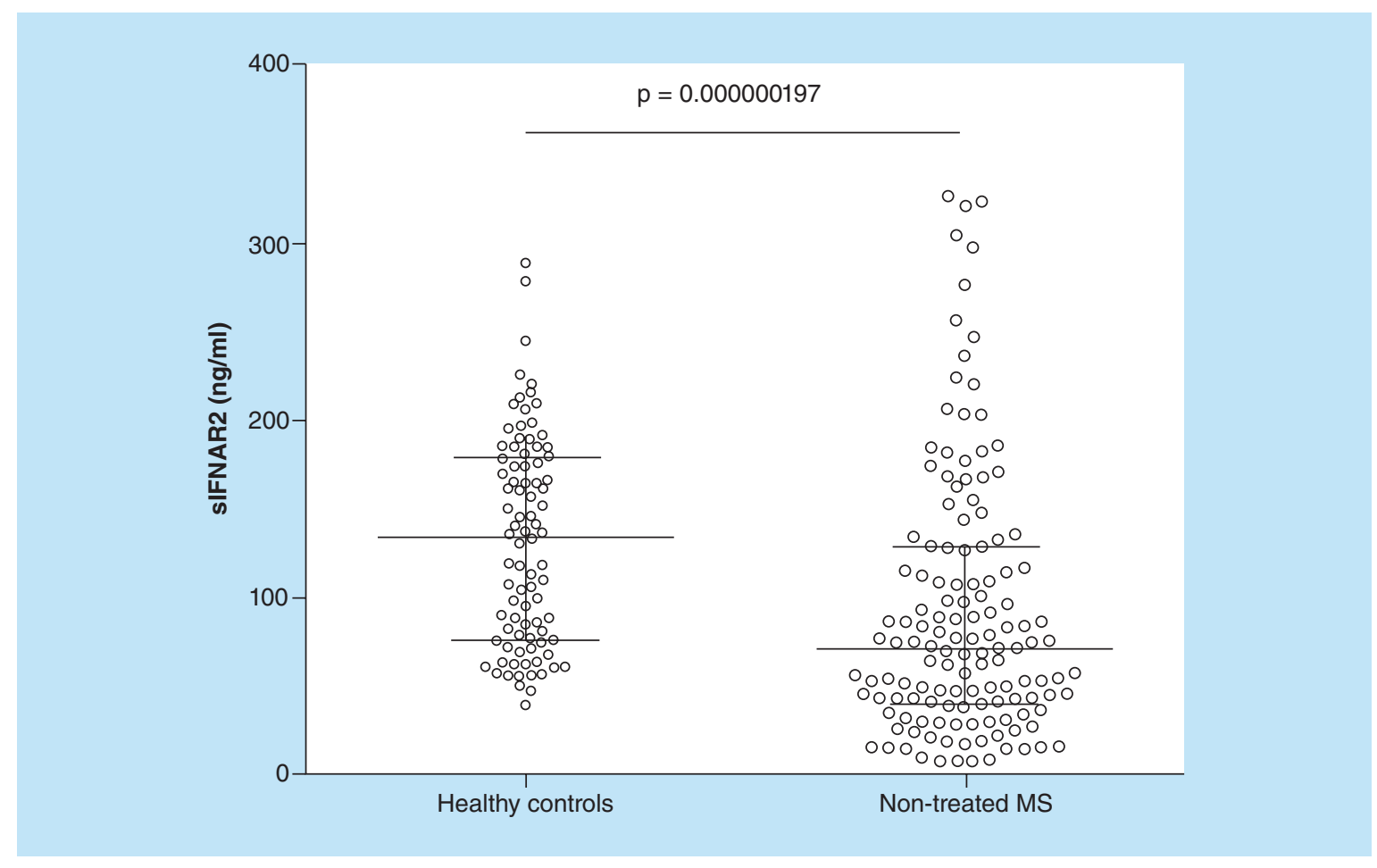

Figure 3. ELISA determination of sIFNAR2 concentration in serum of non-treated MS patients and healthy controls.

ity of the assay for analyzing archival blood samples up to this time.

Once the protocol was validated, we measured sIFNAR2 in serum from MS patients and HC. An abundance of soluble circulating cytokine receptors has been reported, with sIFNAR2, among them [14,26]. Almost all samples analyzed had detectable sIFNAR2 levels within the range of our ELISA, explained by the fact that the IFN- $\beta$ receptor (IFNAR) is ubiquitously expressed on most cell types [4,27] and sIFNAR2 is an isoform resulting from alternative processing of the human IFNAR2 gene product $[28,29]$.

The sIFNAR2 measurements with our validated ELISA showed that MS patients, who had not been treated with IFN- $\beta$ had lower circulating sIFNAR2 levels than HC. While developing the validation of the assay, a commercial kit for sIFNAR2 was released. Our recombinant sIFNAR2 was detected in the commercially available sIFNAR2 ELISA kit, and the standard protein of this commercial kit was detectable with our ELISA. Moreover, some of the samples were analyzed with both ELISAs, showing that differences between MS patients and HC followed the same pattern. To our knowledge, only one previous study found increased sIFNAR2 levels in IFN- $\beta$-treated patients compared with HC by ELISA [30], although details of the method and the standards used were not described.
The present study demonstrated a significant increase in serum sIFNAR2 in HC compared with untreated MS patients, with a slight degree of overlapping in the distribution of the marker in both populations. Additional studies are needed to evaluate the role of sIFNAR2 as a useful biomarker for the diagnosis or differential diagnosis in MS. If so, it will have the advantage of being detected in serum, unlike most accurate diagnostic markers previously described in MS such as oligoclonal IgG bands [31,32], free kappa light chain [32] or chitinase 3-like 1 [33], which are found in cerebrospinal fluid.

\section{Conclusion}

The validation data characterize this ELISA as a suitable method for the quantification of the soluble isoform of the IFNAR2 receptor in human serum. The availability of this sandwich ELISA will provide consistent results for assessment of sIFNAR2 concentrations in MS, representing a practical tool for further studies aimed to explore the implication of sIFNAR2 in MS and other immunological diseases.

\section{Future perspective}

Soluble receptors of cytokines normally participate in the control of cytokine activity and the ability of binding to the cytokine have prompted interest in their use as therapeutic agents. However, the soluble isoform of 
IFN- $\beta$ receptor (sIFNAR2), which is able to modulate the activity of both endogenous and systemically administered IFN- $\beta$, remains poorly studied in multiple sclerosis, notwithstanding the evidence that IFN- $\beta$ plays an important role in the pathogenesis of the disease.

The development of this validated ELISA has shown differential levels of sIFNAR2 in untreated MS patients and healthy controls that encourage for further research to elucidate the possible role of this soluble receptor in the MS pathogenesis and its potential use as diagnostic biomarker.

Nowadays, we have an ongoing replication study with a bigger cohort of samples and additionally we are performing several experiments to test the antiviral and immunomodulatory effects of our recombinant protein in vitro.

\section{Supplementary data}

To view the supplementary data that accompany this paper please visit the journal website at: www.future-science.com/ doi/full/10.4155/bio.15.208

\section{Author contributions}

B Oliver-Martos and L Leyva performed study concept and design. T Órpez-Zafra, JL Rodriguez-Bada, MJ Pinto-Medel, I Hurtado-Guerrero performed the experiments. Analysis and interpretation of data was done by B Oliver-Martos, L Leyva, J Pavía. Ó Fernández did clinical evaluation of the patients. Drafting of the manuscript was done by B Oliver-Martos and L Leyva. Critical revision of the manuscript was done by J Pavía Molina, Ó Fernández, E Martín Montañez.

\section{Acknowledgements}

The authors would like to thank all the subjects who participated in this study, and the FEDEM (Fundación Española de Esclerosis Múltiple). We also thank Alfredo Toraño and Cath- erine Mark for their generous technical assistance and the critical revision of the manuscript.

\section{Financial \& competing interests disclosure}

T Órpez-Zafra is supported by grants from Red Temática de Investigación Cooperativa Red Española de Esclerosis Múltiple REEM (RD07/0060 and RD12/0032). This work was supported by grants from Consejería de Igualdad, Salud y Políticas sociales (Junta de Andalucía) to B Oliver-Martos (PI-0267-2013) and by grant of the Instituto de Salud Carlos III co-founded by Fondo Europeo de Desarrollo Regional - FEDER to O Fernández (PI13/00927). Ó Fernández received honoraria as consultant to advisory boards, and as chairman or lecturer in meetings, and has participated in clinical trials and other research projects promoted by Almirall, Actelion, Allergan Bayer-Schering, Biogen-Idec, Novartis, Merck-Serono, Roche and Teva. The authors have no other relevant affiliations or financial involvement with any organization or entity with a financial interest in or financial conflict with the subject matter or materials discussed in the manuscript apart from those disclosed.

No writing assistance was utilized in the production of this manuscript.

\section{Ethical conduct of research}

The authors state that they have obtained appropriate institutional review board approval or have followed the principles outlined in the Declaration of Helsinki for all human or animal experimental investigations. In addition, for investigations involving human subjects, informed consent has been obtained from the participants involved.

\section{Open access}

This work is licensed under the Attribution-NonCommercialNoDerivatives 4.0 Unported License. To view a copy of this license, visit http://creativecommons.org/licenses/by-ncnd/4.0/

\section{Executive summary}

- The soluble isoform of the subunit 2 of the IFN- $\beta$ receptor (sIFNAR2) can bind IFN- $\beta$ and modulate its activity, although its role in autoimmune diseases remains unknown.

- Human recombinant sIFNAR2 protein has been cloned, purified and expressed. This protein has been used as a standard in the development and validation of a suitable ELISA for the quantification of sIFNAR2 in human serum.

- As IFN- $\beta$ plays an important role in the pathogenesis of multiple sclerosis and sIFNAR2 is able to modulate IFN- $\beta$ activity, serum levels of sIFNAR2 were assessed in multiple sclerosis patients and healthy controls.

- Nontreated MS patients show significantly lower circulating sIFNAR2 levels than healthy controls, highlighting the importance that sIFNAR2 could have in MS pathogenesis, and encouraging further studies.

\section{References}

1 Trapp BD, Peterson J, Ransohoff RM et al. Axonal transection in the lesions of multiple sclerosis. N. Engl. J. Med. 338(5), 278-285 (1998).

2 McQualter JL, Bernard CC. Multiple sclerosis: a battle between destruction and repair. J. Neurochem. 100(2), 295-306 (2007).
3 Compston A, Coles A. Multiple sclerosis. Lancet 372(9648), 1502-1517 (2008).

4 Severa M, Rizzo F, Giacomini E et al. IFN- $\beta$ and multiple sclerosis: cross-talking of immune cells and integration of immunoregulatory networks. Cytokine Growth Factor Rev. 26(2), 229-239 (2015). 
5 Uzé G, Lutfalla G, Bandu MT et al. Behavior of a cloned murine interferon alpha/beta receptor expressed in homospecific or heterospecific background. Proc. Natl Acad. Sci. USA 89(10), 4774-4778 (1992).

6 Cutrone EC, Langer JA. Contributions of cloned type I interferon receptor subunits to differential ligand binding. FEBS Lett. 404(2-3), 197-202 (1997).

7 Pestka S, Langer JA, Zoon KC et al. Interferons and their actions. Annu. Rev. Biochem. 56, 727-777 (1987).

8 Baron S, Tyring SK, Fleischmann WRJ et al. The interferons. Mechanisms of action and clinical applications. JAMA 266(10), 1375-1383 (1991).

9 Rose-John S, Heinrich PC. Soluble receptors for cytokines and growth factors: generation and biological function. Biochem. J. 300 (Pt 2), 281-290 (1994).

10 Fernandez-Botran R, Chilton PM, Ma Y. Soluble cytokine receptors: their roles in immunoregulation, disease, and therapy. Adv. Immunol. 63, 269-336 (1996).

11 Fernandez-Botran R. Soluble cytokine receptors: novel immunotherapeutic agents. Expert Opin. Invest. Drugs 9(3), 497-514 (2000).

12 Domanski P, Witte M, Kellum M et al. Cloning and expression of a long form of the beta subunit of the interferon alpha beta receptor that is required for signaling. J. Biol. Chem. 270(37), 21606-21611 (1995).

13 Novick D, Cohen B, Tal N et al. Soluble and membraneanchored forms of the human IFN-alpha/beta receptor. J. Leukoc. Biol. 57(5), 712-718 (1995).

14 Novick D, Cohen B, Rubinstein M. Soluble interferon-alpha receptor molecules are present in body fluids. FEBS Lett. 14(3), 445-448 (1992).

15 Peleg-Shulman T, Roisman LC, Zupkovitz G et al. Optimizing the binding affinity of a carrier protein: a case study on the interaction between soluble ifnar 2 and interferon beta. J. Biol. Chem. 279(17), 18046-18053 (2004).

16 McKenna SD, Vergilis K, Arulanandam AR et al. Formation of human IFN-beta complex with the soluble type I interferon receptor IFNAR-2 leads to enhanced IFN stability, pharmacokinetics, and antitumor activity in xenografted SCID mice. J. Interferon Cytokine Res. 24(2), 119-129 (2004).

17 Hardy MP, Owczarek CM, Trajanovska S et al. The soluble murine type I interferon receptor Ifnar- 2 is present in serum, is independently regulated, and has both agonistic and antagonistic properties. Blood 97(2), 473-482 (2001).

18 Polman CH, Reingold SC, Banwell B et al. Diagnostic criteria for multiple sclerosis: 2010 revisions to the McDonald criteria. Ann. Neurol. 69(2), 292-302 (2011).

19 International Conference on Harmonization of Technical Requirements for Registration of Pharmaceuticals for
Human Use (ICH) (2005) Validation of analytical procedures: text and methodology Q2(R1). www.ich.org

20 Lee JW, Devanarayan V, Barrett YC et al. Fit-for-purpose method development and validation for successful biomarker measurement. Pharm. Res. 23(2), 312-328 (2006).

21 Valentin MA, Ma S, Zhao A et al. Validation of immunoassay for protein biomarkers: bioanalytical study plan implementation to support pre-clinical and clinical studies. J. Pharm. Biomed. Anal. 55(5), 869-877 (2011).

22 Lee JW, Hall M. Method validation of protein biomarkers in support of drug development or clinical diagnosis/prognosis. J. Chromatogr. B Analyt. Technol. Biomed. Life Sci. 877(13), 1259-1271 (2009).

23 Mizukoshi E, Kaneko S, Kaji K et al. Serum levels of soluble interferon alfa/beta receptor as an inhibitory factor of interferon in the patients with chronic hepatitis C. Hepatology 30(5), 1325-1331 (1999).

24 Ambrus JL, Ambrus JLJ, Chadha S et al. Mechanism(S) of interferon inhibitory activity in blood from patients with AIDS and patients with lupus erythematosus with vasculitis. Res. Commun. Mol. Pathol. Pharmacol. 96(3), 255-265 (1997).

25 Ambrus JLS, Dembinski W, Ambrus JLJ et al. Free interferon-alpha/beta receptors in the circulation of patients with adenocarcinoma. Cancer 98(12), 2730-2733 (2003).

26 Oppenheim JJ. Cytokines: past, present, and future. Int. J. Hematol. 74(1), 3-8 (2001).

27 Uzé G, Schreiber G, Piehler J et al. The receptor of the type I interferon family. Curr. Top Microbiol. Immunol. 316, 17-95 (2007).

28 Cohen B, Novick D, Barak S et al. Ligand-induced association of the type I interferon receptor components. Mol. Cell Biol. 15(8), 4208-4214 (1995).

29 Novick D, Cohen B, Rubinstein M. The human interferon alpha/beta receptor: characterization and molecular cloning. Cell 77(3), 391-400 (1994).

30 Chadha K, Weinstock-Guttman B, Zivadinov R et al. Interferon inhibitory activity in patients with multiple sclerosis. Arch. Neurol. 63(11), 1579-1584 (2006).

31 Villar LM, Masjuan J, Sadaba MC et al. Early differential diagnosis of multiple sclerosis using a new oligoclonal band test. Arch. Neurol. 62 (4), 574-577 (2005).

32 Villar LM, Espi o M, Costa-Frossard L et al. High levels of cerebrospinal fluid free kappa chains predict conversion to multiple sclerosis. Clin. Chim. Acta 413(23-24), 1813-1816 (2012).

33 Comabella M, Fernández M, Martin R et al. Cerebrospinal fluid chitinase 3-like 1 levels are associated with conversion to multiple sclerosis. Brain 133(Pt 4), 1082-1093 (2010). 